Original scientific paper

\title{
ANALYSIS OF THE FORCE RESPONSE OF A DOUBLE- CANOPY HYDRAULIC SUPPORT UNDER IMPACT LOADS
}

\author{
Meng, Z. S. ; Zhang, J. M. ; Xie, Y. Y. **; Lu, Z. G. ${ }^{* * *, \# ~ \& ~ Z e n g, ~ Q . ~ L . ~}{ }^{* * * *}$ \\ ${ }^{*}$ State Key Laboratory of Mining Disaster Prevention and Control Cofounded by Shandong Province \\ and the Ministry of Science and Technology, Shandong University of Science and Technology, \\ 266590 Qingdao, China \\ ${ }^{* *}$ College of Civil Engineering and Architecture, Shandong University of Science and Technology, \\ 266590 Qingdao, China \\ *** College of transportation, Shandong University of Science and Technology, 266590 Qingdao, China \\ **** College of Mechanical and Electronic Engineering, Shandong University of Science and \\ Technology, 266590 Qingdao, China \\ E-Mail: zhenguolu@ @sdust.edu.cn ( ${ }^{\#}$ Corresponding author)
}

\begin{abstract}
Hydraulic support is an important support equipment used in coal mining. However, it is easily damaged under impact loads. To improve its support stability, the force response of the hydraulic support was investigated by applying different impact load on the double-canopy. Dynamic simulation model based on rigid-flexible coupling was established. In the simulation, the base was treated as rigid, other parts were treated as flexible, and the cylinders were replaced using a stepless variable stiffness system. A parallel static load was applied to the canopies, stiffness characteristics of the support was tested. The force transmission law of the support joints was obtained by applying impact loads to different positions on the canopies. The results indicate that the support shows obvious variable stiffness characteristics under parallel static loads, the rear canopy bears a higher load than the front canopy. The support joints show different sensitivity to the impact load, the joint between the canopy and goaf shield is the most sensitive (up to 4.95). This study is useful to improve the anti-impact performance and structure optimization of hydraulic support systems.
\end{abstract}

(Received in July 2021, accepted in November 2021. This paper was with the authors 1 month for 1 revision.)

Key Words: Hydraulic Support, Impact Load, Force Response, Double-Canopy

\section{INTRODUCTION}

Coal is the most important fossil energy resource for China. By 2050, it is estimated that coal resources will still account for more than $54 \%$ of China's energy consumption. Within the foreseeable future, the safe and efficient mining of coal is still an important subject for the further development of China's coal industry $[1,2]$.

Hydraulic powered support is the only proven and effective support equipment to ensure safe underground mining operations. During the mining process, hydraulic support is mainly used to hold up the roof and provides a safe environment for underground mining operations [3]. Therefore, the support stability of hydraulic support equipment is one of the key factors determining the safety of underground mining. When hydraulic support is in use underground, it is always in a state of dynamic balance with the roof. During normal mining operations, the hydraulic support mainly bears the static gravity load from the roof. However, in the periodic weighting stage, the violent movement of the roof will create a strong impact load on the hydraulic support. This impact load will reduce the performance of the support, or even damage the support, which is not conducive to the support stability. Especially in recent years, with the continuous consumption of shallow coal resources, coal mining engineering has gradually developed to the deeper earth. In addition, with the continuous development of mining technology, the underground mining intensity and mining height have increased significantly. These all lead to an increase in the frequency and strength of the impact load acting on the 
support, which in turn puts forward higher requirements for the anti-impact performance of the hydraulic support [4-6]. The connecting joints of the hydraulic support are the most sensitive structural to the impact load [7]. Studying the force response characteristics of hydraulic support joints under impact load will help in designing high-performance anti-impact support to ensure safe underground mining operations.

In the existing studies, scholars usually regard the hydraulic support as a static support structure, the formation mechanism of stope impact load and its influence on support load are studied $[8,9]$. The static performance of single-canopy hydraulic support have been discussed, the stress and strain distribution of hydraulic support under typical load conditions is obtained [10-12]. Few studies have reported the dynamic behaviour of hydraulic support under impact load. Therefore, this study discusses the force transmission law of the hydraulic support joints when the impact point load acts on the double-canopy.

\section{STATE OF THE ART}

Since the impact load has a significant influence on the support stability of hydraulic support, scholars from across the world have performed a lot of research in this field. In order to obtain the influencing factors of impact load acting on hydraulic support, Yang et al. [13] analysed the disaster mechanism of the mining face by establishing a mathematical model and pointed out that the impact load on a hydraulic support depends on the mining height and top coal integrity. Tan et al. [14] discussed the factors affecting coal deformation by conducting laboratory tests and proposed a new bursting liability index to calculate the impact energy on the support. Cheng et al. [15] analysed the relationship between geological dip angle, working face advancing speed and hydraulic support load. He pointed out that properly increasing the mining progress will reduce the impact load borne by the hydraulic support.

To analyse the dynamic response of hydraulic support system, Szurgacz and Brodny [16] carried out dynamic loading experiments on the support leg by setting up a drop-weight tester. Dynamic responses of the legs were obtained by placing the tester at different heights (from $0.3 \mathrm{~m}$ to $0.5 \mathrm{~m}$ ). He concluded that the impacting load on the hydraulic support first damages the leg system. Liang et al. [17] first proposed a rigid-flexible coupling simulation method for a single-canopy support. By replacing the legs with a fixed stiffness spring, the force response characteristics of the support under different external loads were analysed. By analysing the working process of the hydraulic support, Zeng et al. [18] showed that the support shows yield characteristics in the loading process based on which they put forward a revised simulation scheme. The results showed that the stress state at the equilibrium jack is obviously reduced after the yield stage is introduced. Yang et al., Hu and Xie et al. [19-21] proposed a doublestage linear stiffness equivalent method for the legs; through the simulation of different loading conditions, the vibration characteristics and floor pressure of a single-canopy support were obtained. Ren et al. [22] designed a 1:2 impact loading test-bed to carry out impact loading on a single-canopy support. The dynamic characteristics of the support under concentrated loading in the middle were analysed and the entire experiment process was simulated and verified by ADMAS. Due to the high cost of loading test, only the concentrated loading method is carried out on the support canopy.

Previous studies mainly focused on single-canopy support systems, and the stiffness of the leg and equilibrium jack was usually regarded as equivalent to rigid, fixed stiffness, or doublestage linear stiffness systems. These cannot well describe the varying stiffness characteristics of the hydraulic support legs. In this study, a stepless variable stiffness (SVS) model of the leg system under an isentropic condition was established. Through the equivalent replacement of the leg system, the stiffness characteristics of a double-canopy hydraulic support under static load conditions were analysed. Then, different impact loads were applied to the canopies, the force response of the double-canopy hydraulic support system was obtained. 
The remainder of this paper is arranged as follows. Section 3 presents the numerical method and the SVS modelling method, and different loading methods are also introduced. Section 4 presents the response of the tests of the stiffness response of the support under parallel static load and then discusses the force response characteristics of each joint under dynamic impact loads. Section 5 summarizes the conclusions.

\section{METHODOLOGY}

\subsection{Numerical simulation model of the double-canopy hydraulic support}

A ZC 7000/20/40 type double-canopy hydraulic support was selected to complete the simulation work, and the established numerical model is shown in Fig. 1, where 1 is the base, 2 is the front leg, 3 is the equilibrium jack, 4 is the front canopy (FC), 5 is the simulated roof, 6 is the rear canopy (RC), 7 is the goaf shield, 8 is the front bar, 9 is the rear bar, and 10 is the rear leg. The operational height of the support is set to $4000 \mathrm{~mm}$. The density, Poisson's ratio and Young's modulus of the model are defined as $7860 \mathrm{~kg} / \mathrm{m}^{3}, 0.3$ and $2.1 \mathrm{e} 5 \mathrm{MPa}$, respectively. The gravity load is set vertical toward part 1 . In addition, parts 1 and 5 are defined as rigid, parts 4-9 are meshed as flexile using Hypermesh, while parts 2, 3 and 10 are defined as SVS system. Connections between each of the parts (a e) are defined as kinetics joints (the dynamic friction parameter is 0.5 and the static friction parameter is 0.3 ).

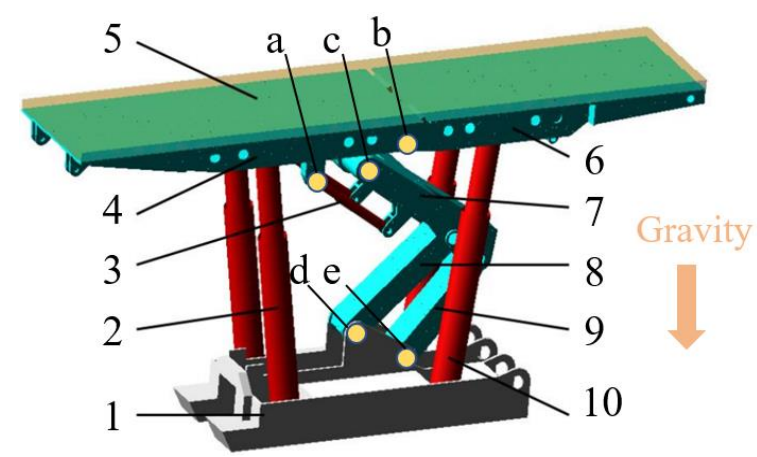

Figure 1: Simulation model of the double-canopy hydraulic support.

\subsection{Definition of the SVS system}

During the supporting process, the canopy bears the gravity load comes from the direct roof directly. This load is transferred to the base and floor through the liquid enclosed in the leg. Under this load, the pressure of the enclosed liquid increases by two times, which leads to an inevitable compression effect. This compression stiffness mainly consists of three parts: the compression of the enclosed liquid $K_{c l}$, the expansion of the cylinder $K_{c w}$, and the compression of the piston rod $K_{m c}$. Thus, the stiffness model of a single-stage cylinder $K_{l s}$ can be expressed as Eq. (1):

$$
K_{l s}=\frac{K_{c l} K_{c w} K_{m c}}{K_{c l} K_{c w}+K_{c l} K_{m c}+K_{c w} K_{m c}}
$$

Assuming this process is isentropic and isobaric, $K_{c w}, K_{m c}$, and $K_{c l}$ can be calculated using Eq. (2).

$$
\left.\begin{array}{l}
h_{c w}=\Delta V_{c w} / A=\left[\pi d^{2} y m \Delta P / 2 E\right] /\left(\pi d^{2} / 4\right)=2 m \Delta P y / E \\
h_{c l}=\Delta V_{c l} / A=\left|\kappa \Delta P y \pi d^{2}\right| /\left(\pi d^{2} / 4\right)=\kappa \Delta P y \\
h_{m c}=F_{P} Y / E A_{m c}
\end{array}\right\}
$$


where $F_{P}$ is the external load, $\Delta P$ is the liquid pressure increment caused by the external load, $d$ is the diameter of the hydraulic cylinder, $y$ is the height of the enclosed liquid, $A$ is the sectional area of the hydraulic cylinder, $E$ is the elastic modulus of steel (195 GPa in this study), $Y$ is the effective height of the leg piston rod, $\kappa$ is the liquid volume compressibility, $m$ is the intermediate variation coefficient, and $A_{m c}$ is the sectional area of the piston rod. By combing Eqs. (1) and (2), $K_{l s}$ can be written as:

$$
K_{l \mathrm{~s}}=F_{p} /\left(h_{c l}+h_{c w}+h_{m c}\right)=\left(\Delta P \pi d^{2} / 4\right) /\left[\left(\Delta P \pi d^{2} / 4\right) \cdot Y / E A_{m c}+2 y m \Delta P / E+\kappa \Delta P y\right]
$$

In this study, a 285-type leg and 160-type equilibrium jack are equipped in the ZC 7000/20/40 type support, and their calculation parameters are shown in Table I.

$$
\begin{aligned}
& K_{e}=\left(\Delta P_{e p l} \pi d^{2} / 4\right) /\left[\left(\Delta P_{e p l} \pi d^{2} / 4\right) \cdot Y+2 y_{e p l} m_{e p l} \Delta P_{e p l} / E+\kappa \Delta P_{e p l} y_{e p l}\right] \quad\left(l_{q} \geq l_{q 0}\right) \\
& K_{e}=\pi E A_{e} /\left[4 \kappa Y_{e} E A_{e} /\left(D_{5}^{2}-d_{5}^{2}\right)+8 m_{e} y_{e p h} d_{5} A_{e} /\left(D_{5}^{2}-d_{5}^{2}\right)^{2}+\pi Y\right] \quad\left(l_{q}<l_{q 0}\right)
\end{aligned}
$$

where $K_{e}$ is the stiffness of the equilibrium jack, $\Delta P_{e p l}$ is the pressure increment of the rodless cavity when the equilibrium jack bears the axial load, $Y_{e}$ is the height of the equilibrium jack piston rod, $D_{5}$ and $d_{5}$ are the outer diameter and inner diameter of the equilibrium jack, $y_{e p l}$ is

\begin{tabular}{|c|c|c|c|c|c|}
\hline \multicolumn{2}{|c|}{ Hydraulic cylinder } & $\begin{array}{c}\text { Diameter of } \\
\text { piston cavity } \\
(\mathrm{mm})\end{array}$ & $\begin{array}{c}\text { Diameter of } \\
\text { piston rod }(\mathrm{mm})\end{array}$ & $\begin{array}{l}\text { Initial enclosed } \\
\text { liquid length } \\
(\mathrm{mm})\end{array}$ & $\begin{array}{c}\text { Piston rod } \\
\text { length }(\mathrm{mm})\end{array}$ \\
\hline \multicolumn{2}{|c|}{ Equilibrium jack } & 160 & 105 & 120 & I \\
\hline \multirow{2}{*}{ Leg } & First stage & 285 & 230 & 970 & 710 \\
\hline & Second stage & 220 & 170 & 990 & 1876 \\
\hline
\end{tabular}
the height of the enclosed liquid in the rodless cavity.

Table I: Main parameters of the leg and the equilibrium jack.

Substituting the parameters in Table I into Eqs. (3) and (4), the stiffness results of the hydraulic cylinders are obtained as shown in Fig. 2. As can be seen, the leg stiffness is relatively large when only the fluid compression stiffness is taken into account (the leg shows smaller displacement). The stiffness curves obtained by removing the $K_{c w}$ and $K_{m c}$ agree well with those obtained by considering only the compression stiffness of the fluid.

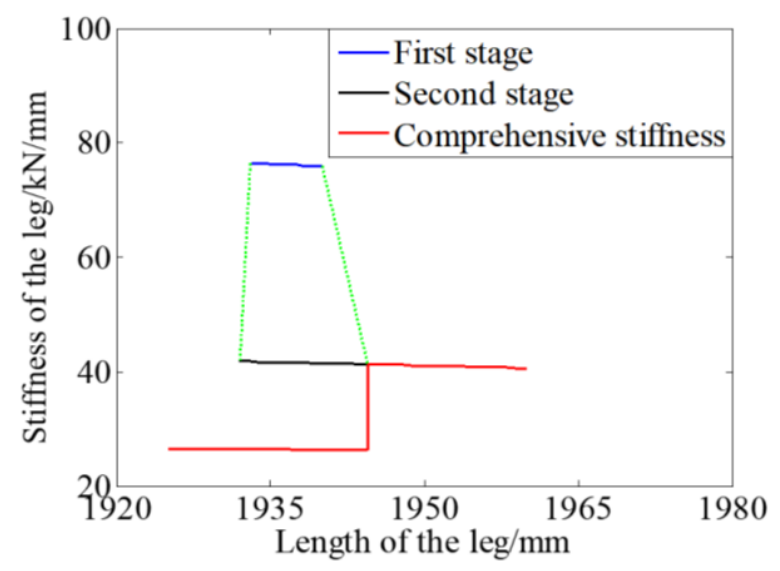

a) The leg

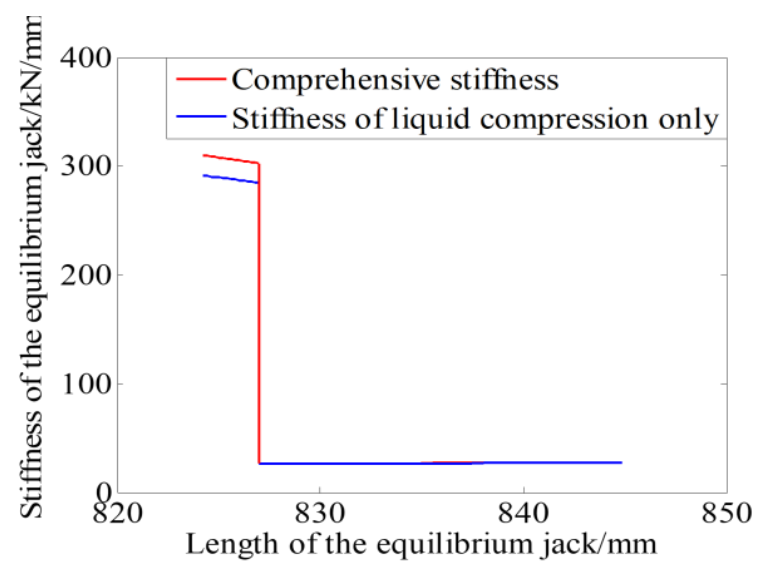

b) The equilibrium jack

Figure 2: Stiffness calculation results.

\subsection{Application of the static load}

To test the static load characteristics of the established simulation model, static loads are applied to the entire canopy $(6500 \mathrm{kN})$ and FC $(3000 \mathrm{kN})$ through the simulated roof, respectively. The 
static loads last for $1 \mathrm{~s}$ as shown in Fig. 3. During the static load condition, the simulated roof is set parallel to the base.

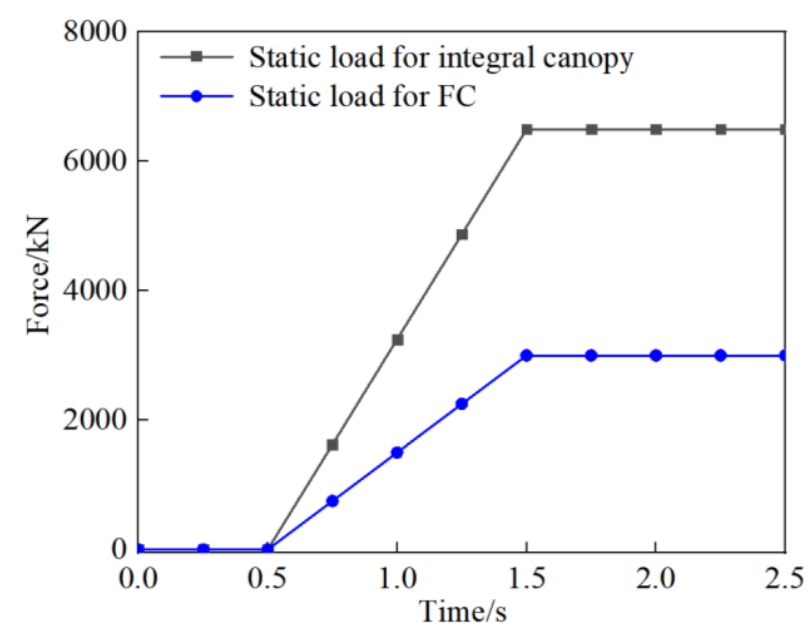

Figure 3: Static load.

\subsection{Application of the impact load}

During the dynamic loading stage, the operating height of the support is set as $3350 \mathrm{~mm}$. To facilitate the extraction of the statistics from the simulation results, the width and length directions of the canopy are defined as the $\mathrm{X}$ and $\mathrm{Y}$ axes, respectively. The impact loading points are arranged with an interval of $350 \mathrm{~mm}$ in the $\mathrm{X}$ direction and $500 \mathrm{~mm}$ in the $\mathrm{Y}$ direction as shown in Fig. 4. There are 45 loading points in the FC and 30 loading points in the RC. According to a previous study [7], when the single point impact load is too large, the support will lose stability and rapidly become damaged. Therefore, the impact load is selected as $400 \mathrm{kN}$ as shown in Fig. 5.

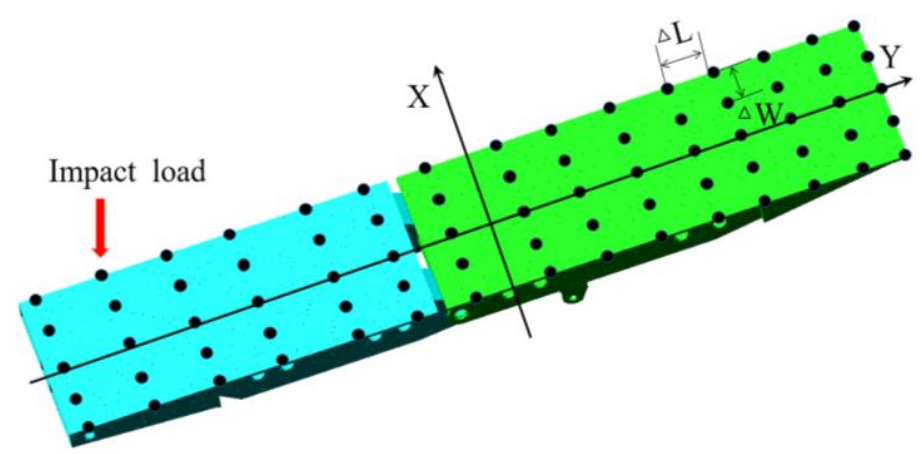

Figure 4: Distribution of impact loading points.

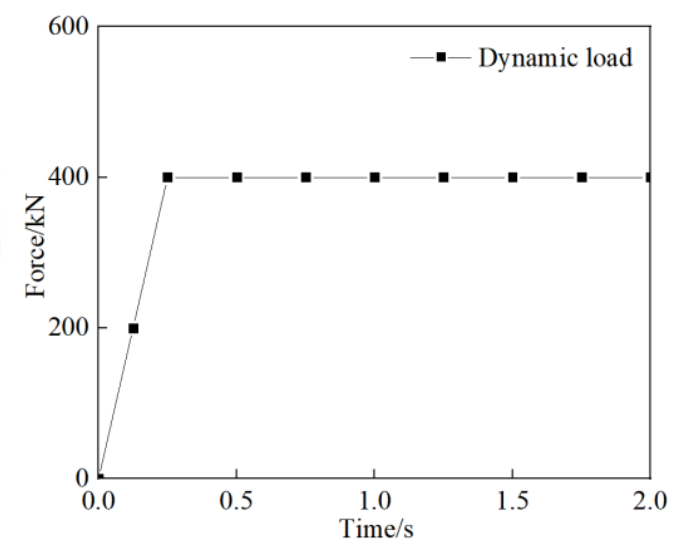

Figure 5: Impact load on the support.

\section{RESULT ANALYSIS AND DISCUSSION}

\subsection{Analysis of the support under static load}

Fig. 6 shows the dynamic response of the support under static load. As can be seen from Fig. 6 a, when the static load $(6500 \mathrm{kN})$ is applied to the entire canopy, the support system reaches the equilibrium state in about $1.6 \mathrm{~s}$, and the steady-state contact force is $6586 \mathrm{kN}$. The initial $0.5 \mathrm{~s}$ is the gravity self-equilibrium stage. During this process, the gravity load on the canopy is very small, and, therefore, the leg basically does not show any displacement (the length of the front 
and rear legs is $2995.9 \mathrm{~mm}$ and $2980.77 \mathrm{~mm}$, respectively). $0.50 \sim 0.89 \mathrm{~s}$ is the active initial support stage of the support. At this stage, the external load increases gradually (up to $522.49 \mathrm{kN}$ ). Since the contact force is less than the active bearing capacity of the secondary cylinder, the canopy basically does not show any displacement. According to the force response of the front and rear legs, although the roof is set as a horizontal settlement, the legs experience an obvious eccentric load effect under the settlement of the canopy. The load on the rear leg is much smaller as compared with that on the front leg due to the rotation angle difference between the legs (the front leg bears $489 \mathrm{kN}$ and the rear leg bears $85 \mathrm{kN}$ ). From $0.89 \mathrm{~s}$ to $1.32 \mathrm{~s}$, the system transitions from the active initial support stage to the passive initial support stage. Meanwhile, the pressure of the second stage cylinder increases gradually to balance the pressure of the first stage cylinder $(1225 \mathrm{kN})$. The secondary cylinder retracts with stiffness $K_{a}$ under the action of the roof contact force (until the front leg retracts to $2978 \mathrm{~mm}$ and the rear leg retracts to $2963 \mathrm{~mm}$ ). Then, the support enters the rapid pressurization stage and acts with cooperative stiffness $K_{b}$. The system finally stabilizes at the contact force of $3424 \mathrm{kN}$ for FC and $3162 \mathrm{kN}$ for RC. The supporting force ratio between the front and rear legs is 1.06, and the overall supporting force of the support is about $6540 \mathrm{kN}$ (slightly greater than the external load due to the equilibrium jack also bearing part of the vertical load). During the entire loading period, the displacement of the front and rear legs is $32.67 \mathrm{~mm}$ and $32.52 \mathrm{~mm}$, respectively. The steady-state displacement difference is not large because of the large stiffness of the leg system.

Fig. $6 \mathrm{~b}$ shows the force and displacement responses of the support under the FC static load $(3000 \mathrm{kN})$. As can be seen, the front leg system also shows obvious sectional load-bearing characteristics; the following stages are also seen: the active initial support stage, the passive initial support stage, and the rapid pressurization stage. Under the static load, the FC contact force reaches $3079 \mathrm{kN}$ (including the gravity load of the canopy and the simulated roof), and the steady state response force of the front legs reaches $3056 \mathrm{kN}$. The retraction of the leg is $28.21 \mathrm{~mm}$ during the entire loading cycle.

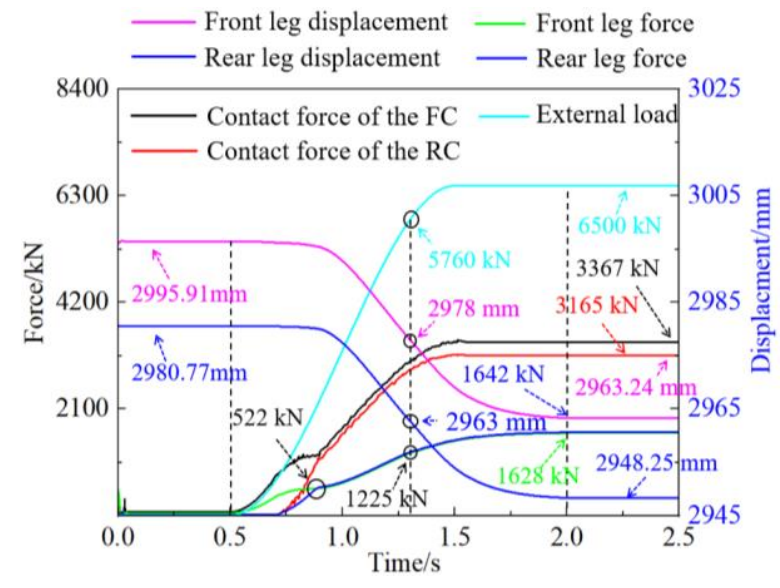

a) Static load for entire canopy

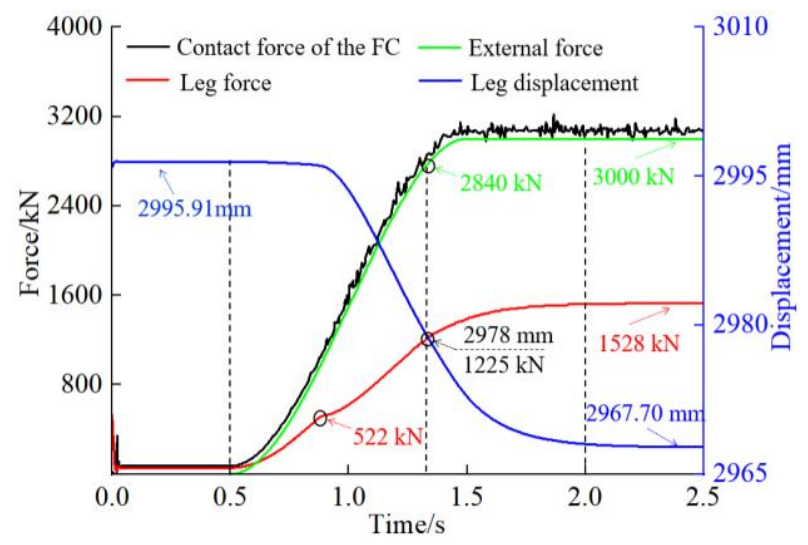

b) Static load for FC

Figure 6: Dynamic response of the support under static load.

\subsection{Analysis of the leg and equilibrium jack under impact load}

Impact loads are applied to the FC and RC respectively, and the results are shown in Figs. 7 and 8. Since the legs and equilibrium jacks are symmetrically arranged, the calculation results are strictly symmetrically distributed when the external load moves along the Y direction. The force response ratio of the non-loading side leg of the FC is bounded by the leg action line, showing the trend of decreasing first and then increasing; however, during this process, the leg force of the loading side is always decreasing. The legs on the loading side show the highest 
load response. Regardless the move direction of the external load, the load response of the legs on the RC side shows a tendency to first decrease and then increase, without a clear boundary. The leg force response on the loading side is slightly higher than that of the non-loading side (about 0.08). A comprehensive comparison of the force response shows that when the external load moves along the $\mathrm{Y}$ direction, the leg force response on the FC side is significantly higher than that on the RC side (the force response ratio on the FC side fluctuates between 1.10 and 1.46, and the leg response ratio on the RC side is always less than 0.5). Due to the RC not having a separate bearing structure, only part of the load is passed on to the RC through joint $b$ (as shown in Fig. 1) when the impact load is applied to the FC. Joint b is subject to the torsional force generated by the deformation of the FC when the external load is acting on the asymmetrical side, which in turn forms a deformation load on the RC. In terms of the equilibrium jack, the response ratio basically does not change when the external load moves along the $\mathrm{X}$ direction. The force response ratio fluctuates between -1.15 and 2.05 when the external load moves from front to back along the Y direction.

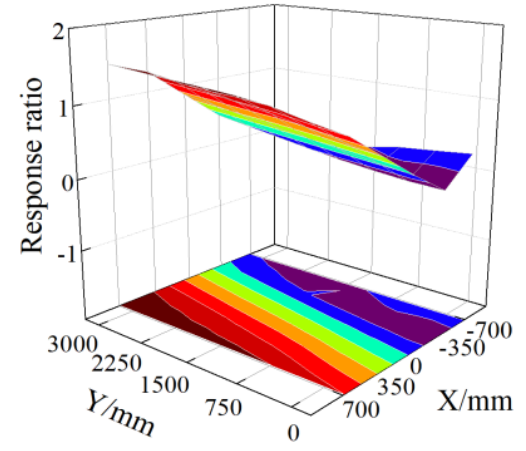

a) Left front leg

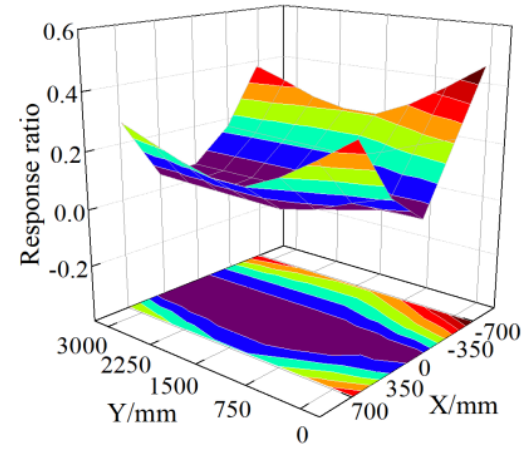

d) Right rear leg

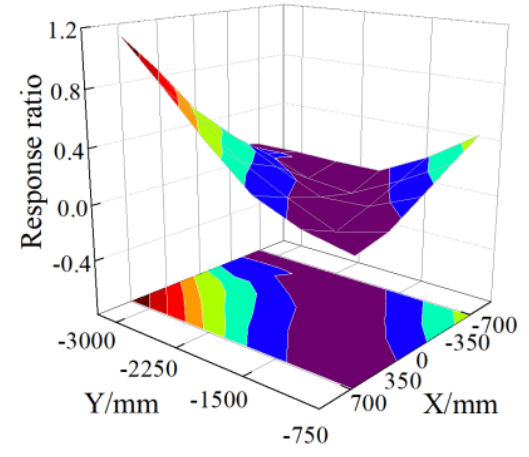

b) Right front leg

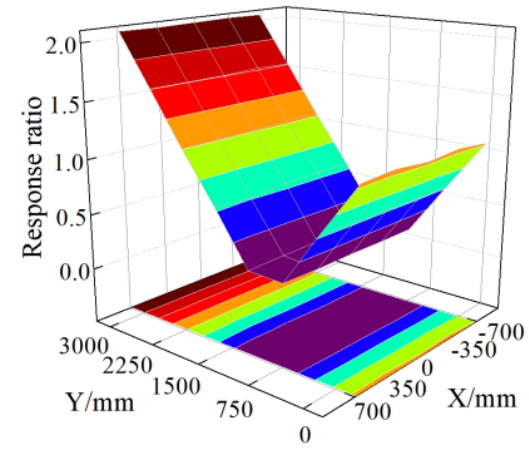

e) Left equilibrium jack

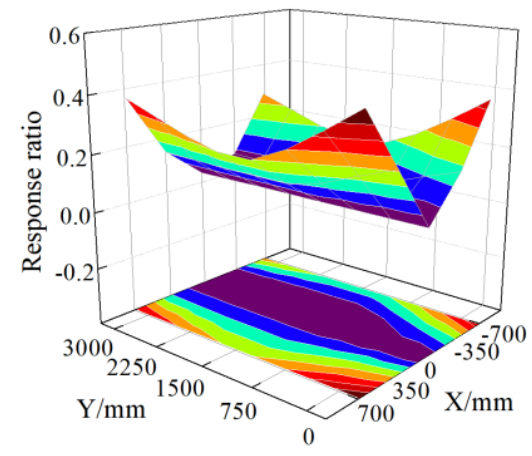

c) Left rear leg

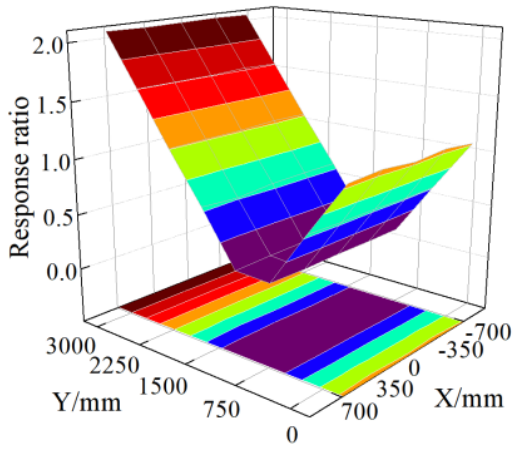

f) Right equilibrium jack

Figure 7: Dynamic response of the leg and equilibrium jack under FC impact load.

Similar conclusions can also be obtained from Fig. 8. When the impact load moves along the $\mathrm{Y}$ direction of the $\mathrm{RC}$, the leg force response ratio also first decreases and then increases. The liquid encloses in the equilibrium jack will quickly overflow when the impact load moves away from the legs. The difference is that since there is no equilibrium jack on the RC side, the $\mathrm{RC}$ produces a large additional force on the legs on the FC side and the equilibrium jacks. The maximum additional force appears on the loading side. The force response ratio of the equilibrium jack (about 2.2) is much higher than that of the legs (about 1.4). 


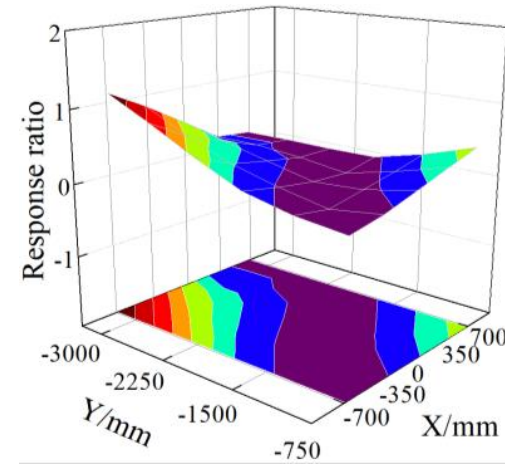

a) Left front leg

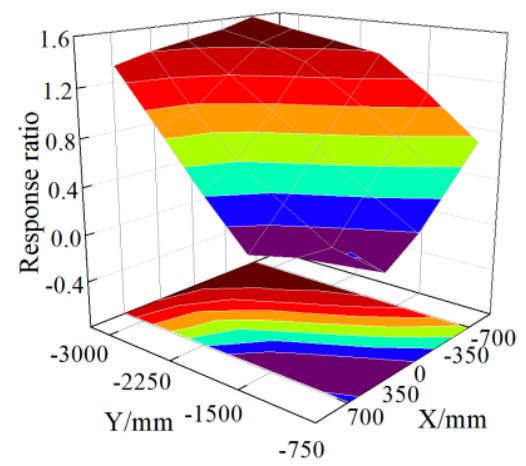

d) Right rear leg

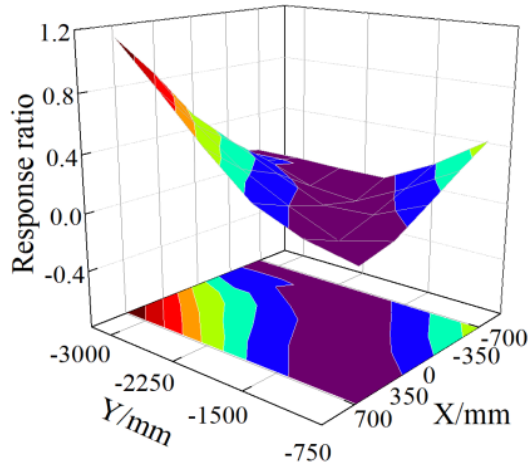

b) Right front leg

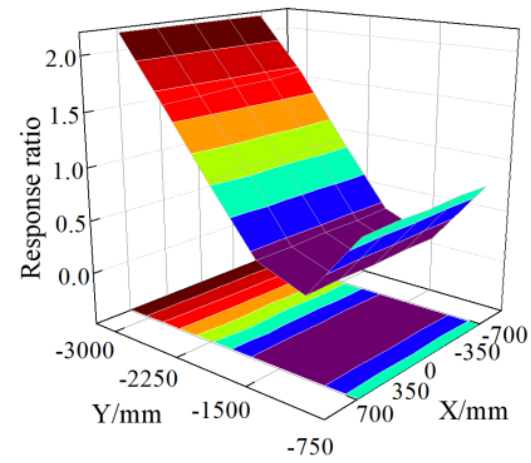

e) Left equilibrium jack

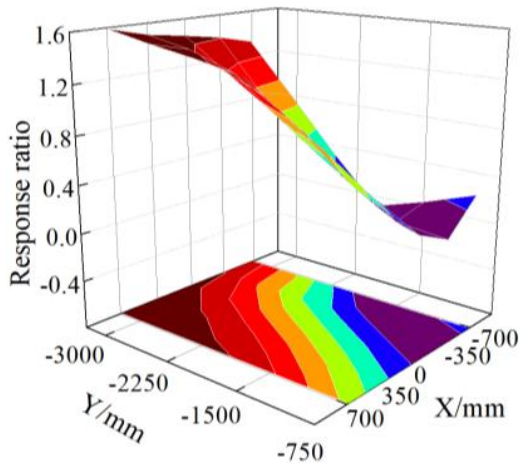

c) Left rear leg

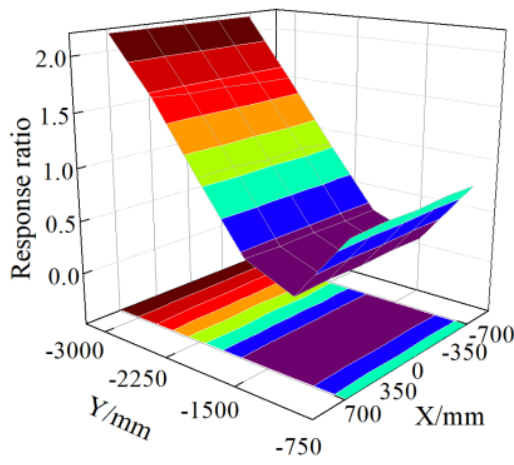

f) Right equilibrium jack

Figure 8: Dynamic response of the leg and equilibrium jack under RC impact load.

\subsection{Analysis of joint $b$ under impact load}

Fig. 9 shows the force response ratio distribution of joint $b$. As can be seen, when the impact load is applied to the FC, only a small part of the load is transmitted to joint b due to the existence of the equilibrium jack (the force response ratio fluctuates between 0.12 and 0.23 ). When the impact load moves along the $\mathrm{X}$ direction, the joint force changes slightly. When the impact load is applied to the RC, it forms an additional torque. This torque will eventually be transmitted to the equilibrium jack on the FC side through joint $b$ to form a self-equilibrium structure. Then, the load response ratio of joint $b$ can reach 1.42 . This ratio can be reduced to 0.17 when the impact load acts near the legs. Through comprehensive comparative analysis of Figs. 11 and 12, it can be noted that the additional torque load transmitted to the FC side is consistent with the response change of the front leg. When the external load is applied to the ends of the canopy, the load-bearing capacity of the RC completely depends on the support performance of the FC side.

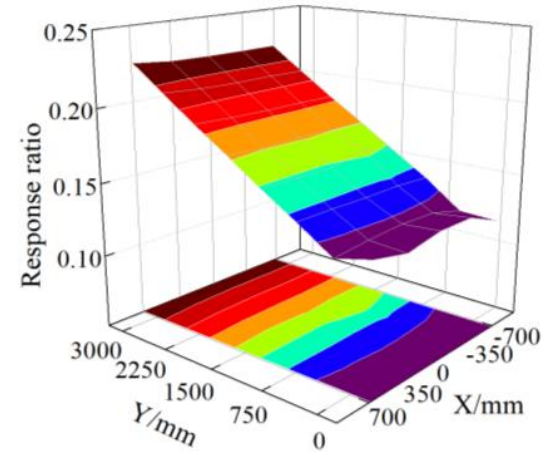

a) FC impact load

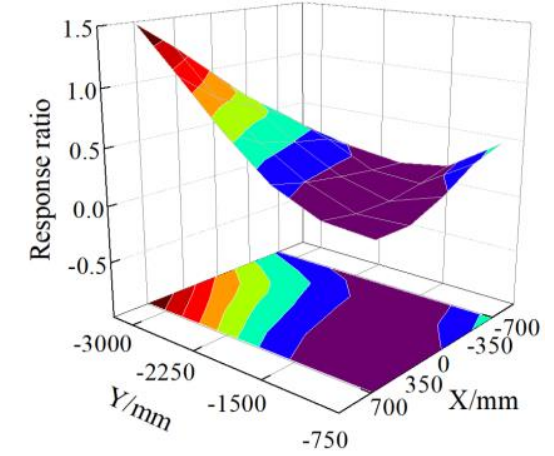

b) RC impact load

Figure 9: Dynamic response of joint b under impact load. 


\subsection{Result analysis of joint $c$ under impact load}

The dynamic response of joint $\mathrm{c}$ when the impact load occurs is shown in Fig. 10. Since the goaf shield is arranged in the middle as a single connecting rod, when the impact load moves along the $\mathrm{X}$ direction, the force response ratio of joint $\mathrm{c}$ basically does not change (the ratio fluctuates between 4.185 and 4.1925). When the impact load moves along the $Y$ direction (from the far leg end to the near leg end), the response ratio of joint $\mathrm{c}$ is basically the same as that of the equilibrium jack. The difference is that, as compared to the equilibrium jack, the response ratio of joint $\mathrm{c}$ is significantly higher (the response ratio of the equilibrium jack is about 2.2, while the ratio of joint $\mathrm{c}$ reaches up to 4.7). Compared with the positioning pin of the equilibrium jack, joint c bears more additional torque load.

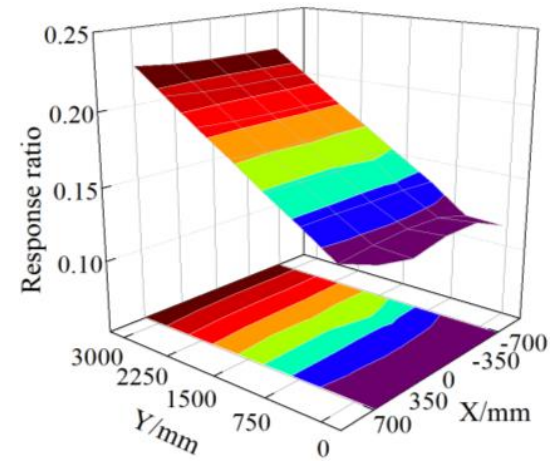

a) FC impact load

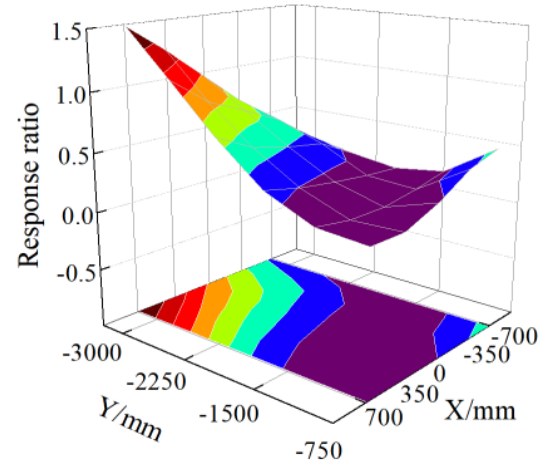

b) RC impact load

Figure 10: Dynamic response of joint $\mathrm{c}$ under impact load.

\subsection{Analysis of joint $d$ and e under impact load}

Joint $\mathrm{d}$ and joint $\mathrm{e}$ are the connections between the lemniscate bars and the goaf shield and base. The force response ratio of the two points are shown in Figs. 11 and 12. Since the arrangement of the lemniscate bars is consistent with that of the goaf shield, the load response ratio of the lemniscate bars also shows strict symmetry in the $\mathrm{Y}$ direction.

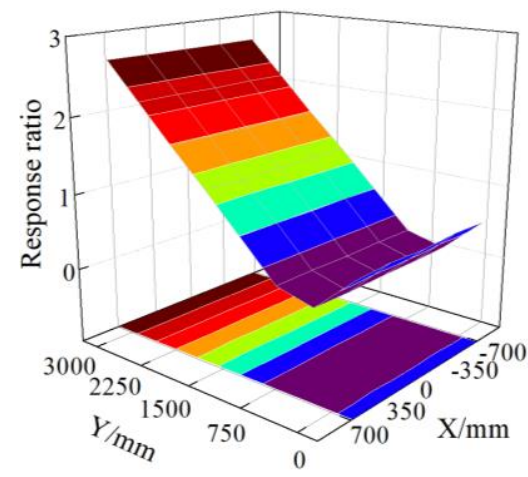

a) FC impact load

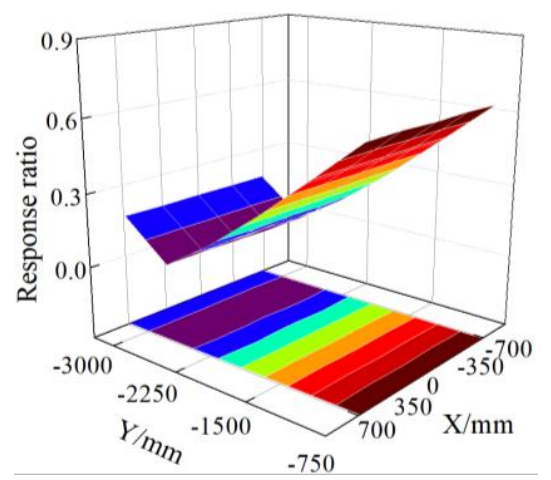

b) RC impact load

Figure 11: Dynamic response of joint d under impact load.

The force response results of joint $\mathrm{d}$ and joint e are compared laterally, and the conclusions are as follows. Under the FC impact load condition, the responses of joint $d$ and joint e are basically the same. The response ratio of joint $\mathrm{e}$ is slightly higher than that of joint $\mathrm{d}$, with both fluctuating between 0.14 and 2.94 . 


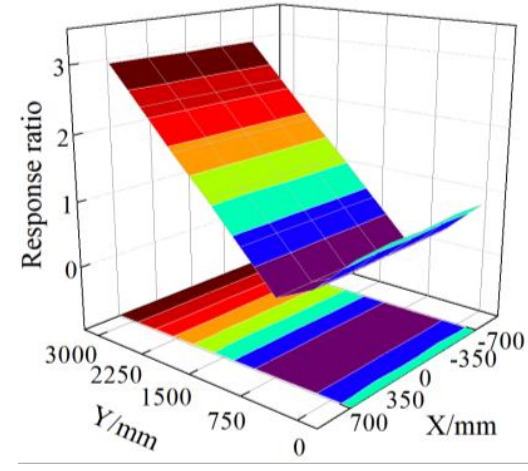

a) FC impact load

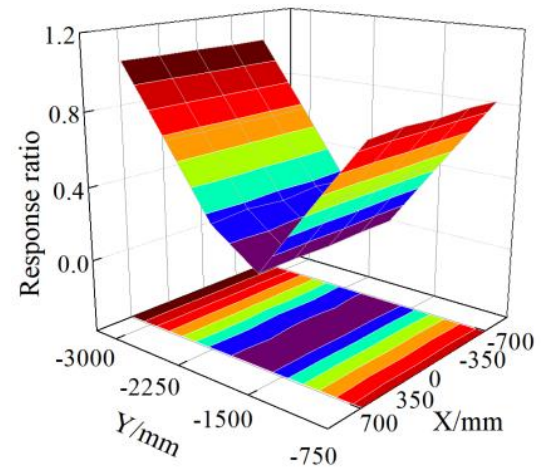

b) RC impact load

Figure 12: Dynamic response of joint e under impact load.

Under the RC impact load condition, the responses of the two joints show obvious differences. When the impact load is applied to the end of the canopy which is near the goaf, joint $b$ bears only a very small dynamic load, and joint e bears most of the load. When the impact load gradually moves close to the coal wall, the force responses of the lemniscate bars continue to decrease. Compared with the FC load condition, the force reverse position of joint $\mathrm{d}$ and joint $\mathrm{e}$ is significantly ahead under the $\mathrm{RC}$ load condition (the force reverse position of joint $d$ is ahead of joint e). By comparing the FC and RC load condition, it can be inferred that the RC impact load has a more destructive influence on the lemniscate bars. Whether under the FC or RC impact load condition, the additional load borne by the lemniscate bars is inversely proportional to the distance from the load to the coal wall.

\section{CONCLUSION}

To study the force response characteristics of a double-canopy hydraulic support system under impact load, a rigid-flexible coupling simulation model was established, and an SVS analysis method was proposed to replace the leg system and the equilibrium jack system. Force responses of the support were obtained by applying static loads and impact point loads to the FC and RC. The conclusions are as follows:

(1) Under the static load condition, the support shows obvious SVS characteristics. In the passive initial support period, the stiffness response of the entire support is about $141.94 \mathrm{kN} / \mathrm{mm}$, while in the rapid resistance increase period, the stiffness response of the entire support is about $88.55 \mathrm{kN} / \mathrm{mm}$. Both are higher than the stiffness of the legs $(81 \mathrm{kN} / \mathrm{mm}$ and $54 \mathrm{kN} / \mathrm{mm})$. Under the horizontal roof settlement condition (the canopies are similar to the fixed connections), the RC side bears a higher load than the FC side.

(2) Different loading points were set on the FC and RC, and the dynamic force response test was carried out by applying an impact load to each point. The joints of the support show different sensitivity to the impact load. Overall, the response ratio of the legs to the impact load is the weakest (about $1.1 \sim 1.46$ ), while joint $b$ has the strongest response to the impact load (about 4.95) followed by the response ratio of the lemniscate bars (about 2.94).

(3) Since there is no equilibrium jack on the RC side of the support, it cannot form a selfequilibrium structure by itself. However, the external load is transmitted to the lemniscate bars through joint $\mathrm{c}$ to form a self-equilibrium attitude structure. The force response of the lemniscate bars under the FC load condition is obviously smaller than that under the RC load condition.

This study is useful to improve the anti-impact performance and structure optimization of hydraulic support systems. However, as a large assembly body, there are inevitable assembly clearances between the hinge points. These assembly clearances worsen the stress state of the 
support and reduce its anti-impact performance. Therefore, in future studies, the force response of hydraulic support with different assembly clearances will be further analysed. In addition, the influence of the support structural parameters on the anti-impact performance will also be discussed in the future.

\section{ACKNOWLEDGEMENT}

This work was supported in part by the Natural Science Foundation of China (Grant Nos. 51974170 and 52104164), and the Natural Science Foundation of Shandong Province (Grant Nos. ZR2019MEE067 and ZR2020QE103).

\section{REFERENCES}

[1] British Petroleum Company (2020). Energy Outlook, 2020 edition, British Petroleum Company, London

[2] British Petroleum Company (2021). Statistical Review of World Energy 2021, $70^{\text {th }}$ edition, British Petroleum Company, London

[3] Kingdom, L.; Hu, X. P.; Liu, X. H.; Yu, X.; Liu, W.; Yu, Y.; Zheng, Z. (2020). Adaptability analysis of four-leg hydraulic support for underhand working face with large mining height of kilometer deep mine, Journal of China Coal Society, Vol. 45, No. 3, 865-878, doi:10.13225/ j.cnki.Jccs.SJ19.1516

[4] Pang, Y. H.; Wang, G. F.; Yao, Q. L. (2020). Double-factor control method for calculating hydraulic support working resistance for longwall mining with large mining height, Arabian Journal of Geosciences, Vol. 12, No. 6, Paper 252, 16 pages, doi:10.1007/s12517-020-5208-0

[5] Zhao, G. Z.; Wang, H.; Song, Y. N.; Zhang, C. S. (2020). Dynamic characteristics study on the two-stage safety valve used on hydraulic support under impact loading, Journal of Theoretical and Applied Mechanics, Vol. 58, No. 3, 623-635, doi:10.15632/jtam-pl/116576

[6] Wu, Q. S.; Jiang, L. S.; Wu, Q. L.; Xue, Y. C.; Gong, B. (2018). A study on the law of overlying strata migration and separation space evolution under hard and thick strata in underground coal mining by similar simulation, DYNA, Vol. 93, No. 2: 175-181, doi:10.6036/8678

[7] Li, T. D.; Wang, J. R.; Zhang, K.; Zhang, C. H. (2020). Mechanical analysis of the structure of longwall mining hydraulic support, Science Progress, Vol. 103, No. 3, 21 pages, doi:10.1177/ $\underline{0036850420936479}$

[8] Pan, W. D.; Nie, X. D.; Li, X. Y. (2019). Effect of premining on hard roof distress behavior: a case study, Rock Mechanics and Rock Engineering, Vol. 52, No. 6, 1871-1885, doi:10.1007/s00603018-1657-0

[9] Cai, W.; Bai, X. X.; Si, G. Y.; Cao, W. Z.; Gong, S. Y.; Dou, L. M. (2020). A monitoring investigation into rock burst mechanism based on the coupled theory of static and dynamic stresses, Rock Mechanics and Rock Engineering, Vol. 53, No. 12, 5451-5471, doi:10.1007/s00603-020$\underline{02237-6}$

[10] Witek, M.; Prusek, S. (2016). Numerical calculations of shield support stress based on laboratory test results, Computers and Geotechnics, Vol. 72, 74-88, doi:10.1016/j.compgeo.2015.11.007

[11] Lin, J. Z.; Yang, T. R.; Ni, K. X.; Han, C. Y.; Ma, H.; Gao, A.; Xiao, C. L. (2021). Effects of boundary conditions on stress distribution of hydraulic support: a simulation and experimental study, Advances in Mechanical Engineering, Vol. 13, No. 3, 16 pages, doi:10.1177/ 16878140211001194

[12] Rajwa, S.; Janoszek, T.; Prusek, S. (2020). Model tests of the effect of active roof support on the working stability of a longwall, Computers and Geotechnics, Vol. 118, Paper 103302, 17 pages, doi:10.1016/j.compgeo.2019.103302

[13] Yang, S. L.; Li, L. H.; Deng, X. L. (2020). Disaster-causing mechanism of roof "topplingslumping" failure in a horizontal sublevel top-coal caving face, Natural Hazards, Vol. 100, No. 2, 757-780, doi:10.1007/s11069-019-03841-8

[14] Tan, Y. L.; Liu, X. S.; Shen, B.; Ning, J. G.; Gu, Q. H. (2018). New approaches to testing and evaluating the impact capability of coal seam with hard roof and/or floor in coal mines, Geomechanics and Engineering, Vol. 14, No. 4, 367-376, doi:10.12989/gae.2018.14.4.367 
[15] Cheng, J.-Y.; Zhang, Y.-D.; Cheng, L.; Ji, M.; Gu, W.; Gao, L.-S. (2017). Study of loading and running characteristic of hydraulic support in underhand mining face, Archives of Mining Sciences, Vol. 62, No. 1, 215-224, doi:10.1515/amsc-2017-0016

[16] Szurgacz, D.; Brodny, J. (2018). Analysis of load of a powered roof support's hydraulic leg, E3S Web of Conferences (XVIII Conference of PhD Students and Young Scientists), Vol. 71, Paper 00002, 5 pages, doi:10.1051/e3sconf/20187100002

[17] Liang, L. C.; Tian, J. J.; Zheng, H.; Jiao, S. J. (2015). A study on force transmission in a hydraulic support under impact loading on its canopy beam, Journal of China Coal Society, Vol. 40, No. 11, 2522-2527, doi:10.13225/j.cnki.jccs.2015.7021

[18] Zeng, Q.-L.; Meng, Z.-S.; Wan, L.-R.; Wang, C.-L. (2018). Analysis on force transmission characteristics of two-legged shield support under impact loading, Shock and Vibration, Vol. 2018, Paper 3854684, 10 pages, doi:10.1155/2018/3854684

[19] Yang, Z. K.; Sun, Z. Y.; Jiang, S. B.; Mao, Q. H.; Liu, P.; Xu, C. Z. (2020). Structural analysis on impact-mechanical properties of ultra-high hydraulic support, International Journal of Simulation Modelling, Vol. 19, No. 1, 17-28, doi:10.2507/IJSIMM19-1-498

[20] $\mathrm{Hu}, \mathrm{X}$. P. (2020). Cooperative automatic control for the canopy posture of a four-leg hydraulic support, International Journal of Simulation Modelling, Vol. 19, No. 4, 713-724, doi:10.2507/ IJSIMM19-4-CO20

[21] Xie, Y. Y.; Meng, Z. S.; Zeng, Q. L.; Yang, C. X.; Gao, K. D. (2020). Analysis of distribution characteristics of study on floor specific pressure of hydraulic support for deep mining based on impact loading, Journal of China Coal Society, Vol. 45, No. 3, 982-989, doi:10.13225/ j.cnki.jccs.SJ19.1541

[22] Ren, H. W.; Zhang, D. S.; Gong, S. X.; Zhou, K.; Xi, C. Y.; He, M.; Li, T. J. (2021). Dynamic impact experiment and response characteristics analysis for 1:2 reduced-scale model of hydraulic support, International Journal of Mining Science and Technology, Vol. 31, No. 3, 347-356, doi:10.1016/j.ijmst.2021.03.004 